\title{
Assessment of a neonatal unit nursing staff: Application of the Nursing Activities Score
}

\author{
Bruna Kosar Nunes ${ }^{1}$ \\ Edi Toma
}

\begin{abstract}
Objective: The study proposes to analyze the nursing staff workload of the sectors of a neonatal unit by means of the Nursing Activities Score - NAS and to calculate the quantitative ideal for the team, comparing it with the current workload. Method: The NAS tool was applied for all newborns interned for at least 24 hours; the sum of the NAS points provided the unit workload which was used for calculating the team assessment by means of mathematical equation. Results: The sector of Low Risk presented a workload of 267 NAS points and an imbalance of 8.8 professionals daily; the Medium Risk sector a workload of 446.7 and an imbalance of 22.3; the High Risk sector a workload of 359 and a deficit of 17.9; the Isolation sector a demand of 609 and an imbalance of 18.2; and NICU a workload of 568.6 with a deficit of 16.1 professionals. Conclusion: The study disclosed an important imbalance of professionals in relation to the exalted work demand they are subjected to daily. The application of the Nursing Activities Score in neonatal units contributes to the evaluation of the workload and assessment of the nursing team.
\end{abstract}

Descriptors: Neonatology; Nursing Human Resources; Nursing Staff; Workload.

\footnotetext{
${ }^{1}$ Specialist in Neonatology, RN, Hospital das Clínicas, Faculdade de Medicina, Universidade de São Paulo, São Paulo, SP, Brazil.

2 PhD, RN, Instituto da Criança, Hospital das Clínicas, Faculdade de Medicina, Universidade de São Paulo, São Paulo, SP, Brazil.
}

Corresponding Author:

Bruna Kosar Nunes

Hospital das Clínicas. Instituto da Criança

Rua Santa Terezinha, 100

Bairro: Jordanópolis

CEP: 09892-340, São Bernardo do Campo, SP, Brasil

E-mail: brunakosar@yahoo.com.br 


\section{Introduction}

The quality in health is defined as the efficient use of the physical and human resources, with the minimum risk for the customer and a high degree of user satisfaction ${ }^{(1)}$. This concept presents particular characteristics for having the human dimension as basic aspect for reaching the established goals, since the deficiency of material resources generates precariousness regarding the work conditions, but the existence, in abundance, of the best material resources does not guarantee quality if there are not adequate human resources, quantitatively and qualitatively.

The efficient use of resources is widely discussed as form of reducing the costs of the health institutions, meaning that for the reduction of the expenses, both the material and the human resources are affected what worries the nursing team tremendously once this represents the quantitatively highest staff percentile of these institutions ${ }^{(2)}$.

The inadequate number of the nursing staff leads to a bigger workload, what causes the increase of the infection incidents in the hospital, of ulcers through pressure, of errors during the patient care giving, prolongs the hospitalization time and raises the costs of the patient treatment ${ }^{(2-3)}$. It is also related to the incorrect assessment of the patient's needs, the inferior standard of the care of the nursing staff, the inappropriateness of the team supervision and the undueness of the registers in the documentation. High workload can generate occupational risks, once that the work requirements become high and the scope of decision taking low, what originates psychological tension $^{(4)}$.

The workload is considered a basic element for the staff number forecast as it allows for identifying how much time is needed to carry out the necessary cares. Moreover, an adequate number of nursing staff is essential since beyond subjecting the team to a lower workload it fosters the accomplishment of an integral care, supplying the patient care necessities and the security of the patient.

There exist means which are capable to quantify this workload, among them the Nursing Activities Score (NAS). The NAS tool was elaborated in 2001, based on the Therapeutic Intervention Scoring System (TISS $^{(5)}$, this last one considered one of the pioneering instruments for the nursing workload quantification. Its translation into Portuguese and validation was made in $2002^{(6)}$.
NAS is composed of 23 items of therapeutic interventions subdivided into the following categories: basic activities; ventilation assistance; cardiovascular assistance; renal assistance; neurological assistance; metabolic assistance and specific interventions. The category of basic activities encloses the family support and care as well as the administrative activities, beyond other activities related to the cares. The NAS score shows how much working time (in percent) the patient required in the last 24 hours, saying a score of 100 means that the patient needed $100 \%$ of the working time of one nursing staff member in order to have the assistance carried out. Transforming into supplied assistance time, every NAS point corresponds to14.4 minutes.

The NAS tool was applied in a neonatal Intensive Care Unit, presenting as result the effectiveness in quantifying the workload in these units and the support in sizing the nursing team ${ }^{(7)}$.

In light of this discussion, considering the managerial dimension of the nursing work process, which has as subject the work organization and the human resources in nursing, in order to implement adequate conditions of patient care and service for the $\operatorname{staff}^{(8)}$, the present study was carried out.

\section{Objectives}

Dimensioning the workforce of nursing professionals for the neonatal unit of a public teaching hospital, comparing it with the size of the current team.

Identifying the workload of the nursing professionals in each sector of the neonatal unit, verifying which of those presents the biggest work overload to the respective team.

\section{Method}

Exploratory study - descriptive modality case study with quantitative approach, realized in the well-baby nursery affiliated to the neonatal maternity unit (BAM) of the Child Institute of Hospital das Clínicas of the Medical School of the University of São Paulo (HC-FMUSP), located in the Central Institute of HC-FMUSP. The BAM consists of 4 sectors: low risk (EBEN) with 23 beds; average risk (EBEL) with 15 beds; high risk (EBEA) with 9 beds; the isolation sector (EBEI), 8 beds, considered as unit of intensive cares and neonatal intensive care NICU (UBER) with 8 beds.

The study was realized only after the approval of the Ethics Committee for Research Projects Analysis 
- CAPPesq - from Hospital das Clínicas of the Medical School of the University of São Paulo (Process 0506/11).

The data collection was carried out on 9 random days in the period of 8 August 2011 and 5 September 2011, verifying the workload per sector through the application of NAS with all the newborns (RN) of the unit in accordance with the inclusion criterion: hospitalization minimum 24 hours, independent of the diagnosis, duration of stay or type of treatment. NAS is based on the care demand in the last 24 hours and therefore the patient records and requested information from the nursing staff who had been giving care directly to the newborns, in case some care had been given which was not registered in the patient record, was used. These professionals only participated in the research after signing the Term of Free Consent - Clarified.

The workload of each sector was quantified by means of the sum of NAS points for each newborn. The statistic analysis of the data allowed for the average and standard divergence calculation, and due to dealing with a short research period, it was opted for executing the calculation of the $1^{\text {st }}$ quartile (25 percent of the data), $3^{\text {rd }}$ quartile (75 percent of the data), and graphical representation, by means of Boxplot, for providing statistical data which make for evaluating the variability of the workload in the sectors. For the accomplishment of the nursing team sizing, the mathematical equation below was used, consisting of the following variables: NAS punctuation of each day (in hours), the working hours and the staff productivity.

Nursing staff sizing "Q"

$$
Q=\frac{\sum N A S i}{t . p}
$$

Legend:

$Q=$ daily nursing staff quantity

$\sum N A S i=$ total NAS (in hours) sector i per day of the data gathering

$t=$ nursing staff working hours ( 6 hours)

$p=$ productivity $(0,80)$

For the figure $t$ the balanced average calculation was carried out, considering the amount of health professionals and the quantity of their working hours in accordance with the type of employment contract, getting as a result the average amount of 6 working hours for each professional.
For the figure $p$, a viable productivity of 0.80 was considered, that means, the effective working time of the neonatal unit professionals is $80 \%$ of the daily workload, the ascertained value in scientific work ${ }^{(9)}$.

After the completion of the nursing team sizing calculation by means of NAS, a comparison of the team available in the institution with the ideal team estimated by resolution COFEN no. 293/04(10), ordinance of the Health Ministry no. 3432/98(11) and resolution ANVISA (RDC) no. $7 / 10^{(12)}$ was accomplished in each sector.

\section{Results}

The sample is composed of 144 newborns, being $64(44.44 \%)$ from the EBEN sector; 28 (19.44\%) from EBEL; 20 (13.9\%) from EBEA; 19 (13.2\%) from NICU; and $13(9.03 \%)$ from the EBEI sector.

Regarding the characterization of the newborns that composed the sample, the bigger part was of the masculine sex $(56.25 \%) ; 45.8 \%$ presented gestational age superior to 38 weeks, whereas the lesser part presented gestational age inferior to 32 weeks (17.36\%), including moderate to extreme premature babies. In relation to the birth weight, $19.44 \%$ presented weight between $2500 \mathrm{~g}$ - 3400g, considered adequate weight; whereas the lesser part (5.5\%) presented extremely low birth weight $(500 \mathrm{~g}-999 \mathrm{~g})$, cases of extreme preterm neonates. The premature birth was present in the majority of the cases where there was some neonatal pathology $(43.82 \%)$, constituting the main health problem of the newborns in the neonatal unit. The congenital diseases were in the lesser part of the cases (2.24\%). Regarding the internment time, most remained less than 7 days $(50 \%)$, the newborns of the low or average risk sectors that only needed an observation period during the first days of life; while $27.08 \%$ of the newborns remained for more than 30 days, the rest $(22.93 \%)$ had an internment time superior to 7 days and inferior to 30 days. The majority of the hospitalized newborns were released from hospital $(97.87 \%)$, whereas a small part were referral cases, mainly newborns with congenital cardiopathy, or death $(2.12 \%)$.

The NAS tool was applied 406 times in the whole neonatal unit during the sample period, being applied 123 times in the EBEL sector, 83 times at EBEN, 77 times at EBEA, 64 times at EBEI and only 59 times at UBER.

Table 1 shows the NAS application, and some derived measures, in the sectors of the neonatal unit: 
Table 1 - Descriptive analysis of the continuous variables (NAS and derived measures) per sector of the neonatal unit. São Paulo, SP, Brazil, 2011

\begin{tabular}{|c|c|c|c|c|c|c|c|c|c|c|c|}
\hline Sector & $\begin{array}{c}\text { Team } \\
\text { day }\end{array}$ & $\begin{array}{l}\text { NAS } \\
\text { daily }\end{array}$ & $\begin{array}{c}\text { NAS } \\
\text { average }\end{array}$ & $\begin{array}{l}\text { NAS } \\
\text { team }\end{array}$ & $\begin{array}{c}\text { Minutes } \\
\text { spent daily }\end{array}$ & $\begin{array}{c}\text { Hours } \\
\text { spent daily }\end{array}$ & $\begin{array}{l}\text { Minutes/ } \\
\text { day/staff }\end{array}$ & $\begin{array}{c}\text { Hours / } \\
\text { day / staff }\end{array}$ & $\begin{array}{c}\text { Hours real / } \\
\text { day/staff }\end{array}$ & Divergence & $\begin{array}{l}\text { NASideal } \\
\text { team / day }\end{array}$ \\
\hline \multicolumn{12}{|l|}{ EBEN } \\
\hline Average & 8.78 & 267.08 & 29.07 & 13.32 & 3845.92 & 64.10 & 443.74 & 7.40 & 5.92 & 4.54 & 175.56 \\
\hline Divergence & 0.83 & 55.78 & 1.38 & 2.80 & 803.19 & 13.39 & 116.47 & 1.94 & 1.55 & 3.12 & 16.67 \\
\hline $1^{\text {st }}$ quartile & 8.00 & 241.80 & 28.60 & 12.00 & 3481.92 & 58.03 & 370.80 & 6.18 & 4.94 & 2.80 & 160.00 \\
\hline $3^{\text {rd }}$ quartile & 9.00 & 270.40 & 30.00 & 13.50 & 3893.76 & 64.90 & 463.14 & 7.72 & 6.18 & 4.90 & 180.00 \\
\hline \multicolumn{12}{|l|}{ EBEL } \\
\hline Average & 8.67 & 446.20 & 32.56 & 22.29 & 6425.28 & 107.09 & 747.76 & 12.46 & 9.97 & 13.62 & 173.33 \\
\hline Divergence & 0.71 & 115.92 & 2.11 & 5.78 & 1669.22 & 27.82 & 212.27 & 3.54 & 2.83 & 5.96 & 14.14 \\
\hline $1^{\text {st }}$ quartile & 8.00 & 350.80 & 31.90 & 17.50 & 5051.52 & 84.19 & 631.44 & 10.52 & 8.42 & 9.50 & 160.00 \\
\hline $3^{\text {rd }}$ quartile & 9.00 & 529.80 & 33.10 & 26.50 & 7629.12 & 127.15 & 865.44 & 14.42 & 11.54 & 17.50 & 180.00 \\
\hline \multicolumn{12}{|l|}{ EBEA } \\
\hline Average & 9.33 & 359.11 & 41.92 & 17.94 & 5171.20 & 86.19 & 561.55 & 9.36 & 7.49 & 8.61 & 186.67 \\
\hline Divergence & 1.12 & 40.78 & 2.27 & 2.03 & 587.27 & 9.79 & 96.29 & 1.60 & 1.28 & 2.40 & 22.36 \\
\hline $1^{\text {st }}$ quartile & 9.00 & 328.20 & 40.70 & 16.40 & 4726.08 & 78.77 & 515.00 & 8.58 & 6.87 & 7.40 & 180.00 \\
\hline $3^{\text {rd }}$ quartile & 1.00 & 393.40 & 42.70 & 19.70 & 5664.96 & 94.42 & 603.36 & 10.06 & 8.04 & 9.90 & 200.00 \\
\hline \multicolumn{12}{|l|}{ EBEI } \\
\hline Average & 12.22 & 609.04 & 85.74 & 30.43 & 8770.24 & 146.17 & 723.45 & 12.06 & 9.65 & 18.21 & 244.44 \\
\hline Divergence & 0.97 & 63.32 & 2.37 & 3.16 & 911.82 & 15.20 & 107.07 & 1.78 & 1.43 & 3.64 & 19.44 \\
\hline $1^{\text {st }}$ quartile & 12.00 & 582.80 & 84.30 & 29.10 & 8392.32 & 139.87 & 658.44 & 10.97 & 8.78 & 16.10 & 240.00 \\
\hline $3^{\text {rd }}$ quartile & 13.00 & 683.70 & 85.90 & 34.10 & 9845.28 & 164.09 & 770.01 & 12.83 & 10.27 & 21.40 & 260.00 \\
\hline \multicolumn{12}{|l|}{ UBER } \\
\hline Average & 12.22 & 568.63 & 86.78 & 28.41 & 8188.32 & 136.47 & 677.68 & 11.29 & 9.04 & 16.19 & 244.44 \\
\hline Divergence & 2.11 & 96.17 & 2.34 & 4.80 & 1384.90 & 23.08 & 102.37 & 1.71 & 1.36 & 3.86 & 42.16 \\
\hline $1^{\text {st }}$ quartile & 12.00 & 504.40 & 85.60 & 25.20 & 7263.36 & 121.06 & 605.28 & 10.09 & 8.07 & 13.70 & 240.00 \\
\hline $3^{\text {rd }}$ quartile & 12.00 & 610.70 & 87.10 & 30.50 & 8794.08 & 146.57 & 732.84 & 12.21 & 9.77 & 18.50 & 240.00 \\
\hline
\end{tabular}

The NAS of the EBEN sector shows an average workload of 267.08 points, being 29.07 ( $6 \mathrm{~h} 58 \mathrm{~min}$ ) per newborn. For this workload the NAS team would be 13.32 staff members/ 24 hours. However, the available daily team has an average of 8.78 professionals, a divergence of 4.54 staff members/ day. For this team the ideal NAS would be 175.56 points. In the EBEL sector, the workload obtained an average of 446.2 NAS points, being 32.56 (7h 50min) per newborn; the NAS team was calculated at 22.29 staff, whereas the daily team is 8.67 , a deficit of 13.62 professionals/ day. For the current team the ideal NAS would be 173.33 points. In the EBEA sector, the workload was at 359.11 points, with 41.92 (10h $5 \mathrm{~min}$ ) per newborn; the calculated NAS team was 17.94 professionals; however the daily team is 9.33, divergence of 8.61 staff members. The ideal NAS in the EBEA sector would be 186.67 points. In the EBEI sector, the average workload was at 609.04 NAS points, with 85.74 (20h $33 \mathrm{~min}$ ) per newborn; the calculated NAS team was 30.43 professionals/ day, but the available daily team is 12.22 , a deficit of 18.21 people. For the current team the ideal NAS would be 244.44 points. The UBER sector had an average workload of 568.63 NAS points, being 86.78 (20h 50min) per newborn; the calculated NAS team was
28.41 staff members, whereas the daily team is 12.22 , a divergence of 16.19 professionals. The ideal NAS for this sector would be 244.44 points.

According to the raised workload in each sector as to NAS, at EBEN 64.10 hours/ day (3845.92 minutes) are used, being 7.40 hours (443.74 minutes) per staff member, taking into consideration the productivity of 0.8 , each staff member spends 5.92 hours/ day; at EBEL 107.09 hours/ day (6425.28 minutes) are used, around 12.46 hours (747.76 minutes) per staff member, taking into consideration the productivity, 9.97 hours per professional; at EBEA 86,19 hours/ day (5171.20 minutes) are used, 9.36 hours (561.55 minutes) each staff member, with the productivity being 7.49 hours per professional; EBEI presents 146.17 hours/ day ( 8770.24 minutes) used, with 12.06 hours (723.45 minutes) per staff member, about 9.65 hours, considering the productivity; and at UBER 136.47 hours/ day (8188.32 minutes) are used, being 11.29 hours (677.68 minutes) per staff member, 9.04 hours considering the productivity.

Boxplot (Figure 1) shows the variation of the daily NAS workload compared to the ideal NAS, calculated for the team available at work: 


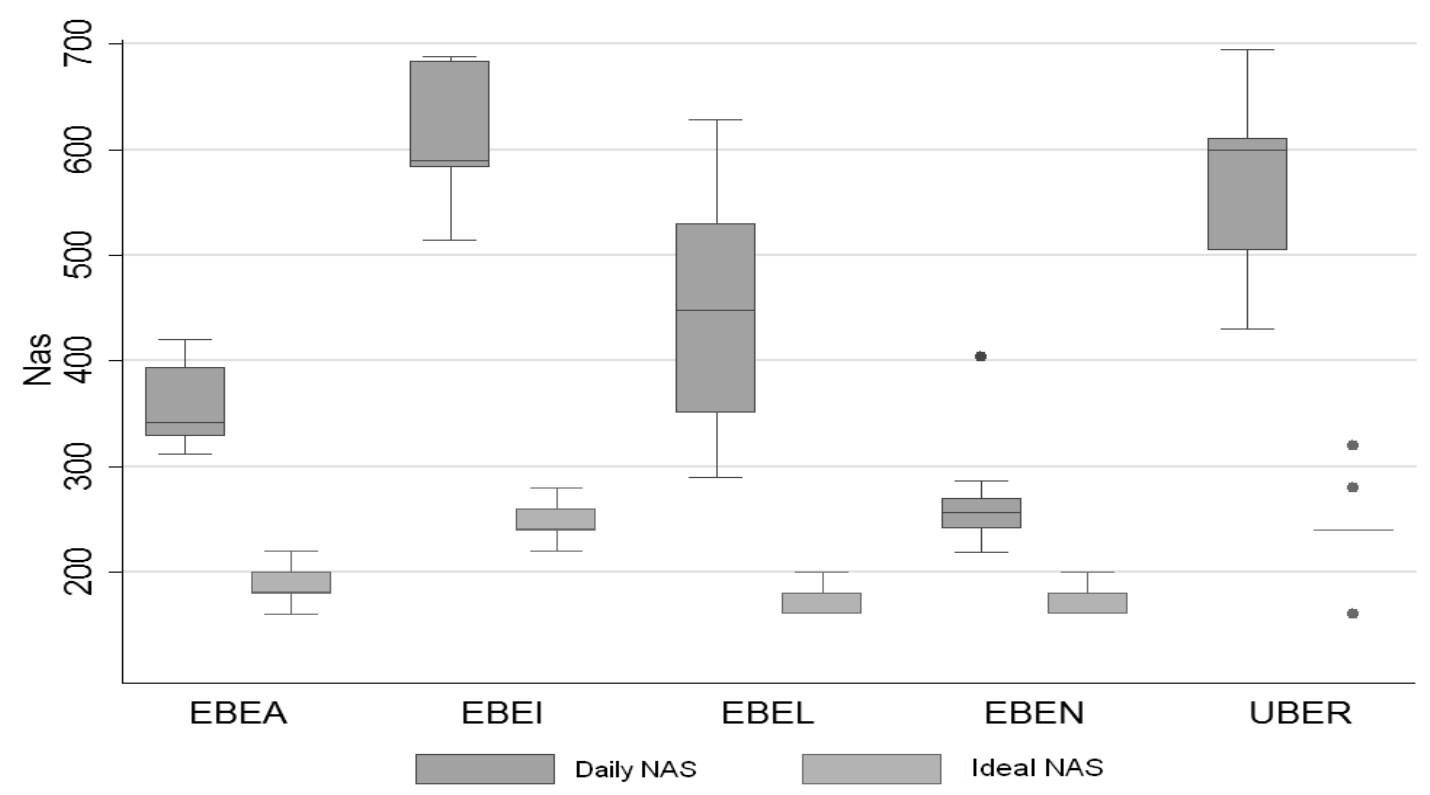

Observation: Ideal NAS calculated according to the number of the team staff members on that

Figure 1 - Boxplot of the daily NAS in relation to the ideal NAS per sector. São Paulo, SP, Brazil, 2011

The boxes (plots) represent the difference between the percentiles 75 and 25 of the NAS obtained in each sector, the line inside each box indicates the median of the workload quantity obtained during the data collection period. The biggest plot regarding the daily NAS was at the EBEL sector, whereas the smallest one was at the EBEN sector. In this last sector, the point outside the plot refers to a day during the data collection where the workload quantity can be considered disparate (figure above the $3^{\text {rd }}$ quartile or below the $1^{\text {st }}$ quartile). The further sectors don't present such variations. The highest plot in the figure is from the EBEI sector, followed by the UBER sector, EBEL, EBEA and finally EBEN. It is as well to observe that the ideal NAS figures are all below the daily NAS, the biggest difference in the EBEI sector.
Boxplot proves the fact that all the sectors have an excessive workload as the daily NAS plots are above the ideal NAS ones. At EBEI this difference is bigger, what characterizes it as the sector where the workload excess is bigger. Moreover, it is characterized as the sector with the biggest workload of the unit due to presenting the highest daily NAS plot. The biggest workload variability is presented at EBEL as it shows the biggest daily NAS plot, whereas EBEN got minor variability for showing the smallest plot and a smaller workload of the unit.

From the nursing staff sizing, calculated through measuring the workload by means of the NAS application, the comparison of the nursing staff quantity defined by effective legislations on the subject is conducted. Table 2 shows the results:

Table 2 - Quantitative nursing staff average, according to available nursing professionals, NAS punctuation, resolution COFEN no. 293/04, ordinance of the Health Ministry no. 3432/98 and resolution ANVISA (RDC) no. 7/10. São Paulo, SP, Brazil, 2011

\begin{tabular}{|c|c|c|c|c|c|c|c|}
\hline Sector & $\begin{array}{c}\text { Sample period } \\
\text { (days) }\end{array}$ & $\begin{array}{l}\text { Newborns } \\
\text { (average) }\end{array}$ & Team Day & Team NAS & $\begin{array}{l}\text { Resolution } \\
\text { COFEN }\end{array}$ & $\begin{array}{c}\text { Ordinance } \\
\text { MS } \\
\text { no. } 3432 \\
\end{array}$ & $\begin{array}{c}\text { RDC no. } 7 \\
\text { ANVISA }\end{array}$ \\
\hline EBEN & 9 & 9.2 & 8.8 & 13.3 & 10.7 & $\mathrm{NA}^{*}$ & $N A^{*}$ \\
\hline EBEL & 9 & 13.7 & 8.7 & 22.3 & 16 & $N A^{*}$ & $N A^{*}$ \\
\hline EBEA & 9 & 8.6 & 9.3 & 17.9 & 16.7 & $N A^{*}$ & $N A^{*}$ \\
\hline EBEI & 9 & 7.1 & 12.2 & 30.4 & 26.5 & 28.4 & 22.2 \\
\hline UBER & 9 & 6.6 & 12.2 & 28.4 & 24.4 & 26.2 & 20.4 \\
\hline
\end{tabular}

*NA $=$ not applicable (sectors not considered intensive care)

Table 2 shows that during the 9 days which constitute the sample period of this study, EBEN presents an average of 9.2 newborns and an available team of 8.8 professionals/ 24 hours, yet the team NAS calculated has an average of 13.3 professionals/ day, and the resolution COFEN, 10.7 professionals, considering it an 
intermediate care sector. In the EBEL sector, the average of newborns was 13.7, with an available team of 8.7, the NAS team has an average of 22.3, whereas the resolution COFEN has 16 staff members, considering it intermediate care. At EBEA, the average of newborns was 8.6, with an available team of 9.3, the team NAS calculated has an average of 17.9 , and the resolution COFEN, considering it semi-intensive care, calculated 16.7 staff members/ day. EBEI shows an average of 7.1 newborns, with an available team of 12.2 , the team NAS calculated has 30.4 professionals, the resolution COFEN, 26.5, in compliance with intensive care, the ordinance of the Health Ministry, 28.4, and the RDC of ANVISA, 22.2 professionals/ day. And at UBER, the average of newborns was 6.6, with an available team of 12.2 , the team NAS shows is 28.4 , the resolution COFEN for intensive care - 24.4, the ordinance of the Health Ministry 26.2, and the RDC of ANVISA establishes 20.4 professionals/ 24 hours.

\section{Discussion}

The distribution of the newborns in the sample discloses that most of them were at EBEN which is a sector of low complexity where the detention time is short, in general 3 days, generating a high newborn fluctuation in the sector, making the data collection from different newborns possible; whereas EBEI presented the lowest amount of newborns in the sample for being a sector where the interned children remain a long time. Although the unit has as one of its main characteristics assistance to preterm neonates, these patients present long time internment and therefore have little variation in the sample of the study, whereas the normal and late deliveries remain on average 3 days in the unit, representing a bigger variation and therefore constitute the biggest part of the newborns in the sample. The application of the NAS tool happened more times in the EBEL sector due to its high occupation level, whereas the UBER sector had the tool applied fewer times due to the lowest occupation level of the other sectors.

It was to observe that all the sectors of the neonatal unit presented a workload superior to the available professionals. Moreover, the staff sizing calculated by means of NAS shows that all the sectors have an imbalance of nursing team professionals. Although the sectors of greater complexity (EBEI and UBER) presented a greater number of nursing team workers, these are the sectors which present a greater imbalance of professionals, EBEI and UBER, respectively, this because in these sectors there is a greater workload. EBEL and EBEA appear subsequently, whereas the EBEN sector presented the lowest workload and the lowest deficit of professionals. This shows that the complexity degree of the patient care intervenes directly in the workload which the nursing professional is submitted to. In a similar study conducted in a University Hospital of São Paulo(7) in the Neonatal Unit, the available team was 20.7, while the NAS team got a figure of 27.1, a deficit of 6.4 professionals/ day. Yet in the neonatal intensive care unit (NICU), the available team was 12 professionals, while the NAS team presented 12.8, a deficit without statistical relevance. In this study, NAS also showed a workload superior to the quantity of available staff, furthermore showing that the complexity of the cares intervenes in the necessity of a greater number of professionals.

The daily invested minutes and hours are bigger in the EBEI and UBER sectors due to the biggest care demand for newborns, followed by the EBEL sector, which presents a high occupation level, shortly after the EBEA sector, and finally the EBEN sector with lesser complexity. Regarding the daily invested minutes and hours per staff member, per day, the EBEL sector demands more time than the others due to its high occupation level, followed by the sectors EBEI, UBER, EBEA and EBEN, this last one with the lowest demand of time for the workers.

The work overload in the nursing team is evidenced by several studies as risk factor for iatrogenesis, having the security of the patient placed at risk and increasing the mortality rate ${ }^{(13)}$. Also, the high workload affects the health of the nursing staff member, influencing the physical and mental wearout of the professional(14). At NICU, nurses with qualification for performing in this unit have influence on the reduction of the mortality of premature and extremely underweight babies, evidencing that both the quantity and the quality of the health professionals influence the evolution of the patient $^{(15)}$.

It was observed in all sectors that the average of nursing professionals calculated by means of NAS is superior to the available average in the unit and the average of professionals required by the legislation. The sizing with the lowest staff quantity was calculated by the RDC no. 7/10 (12), therefore this standardizes a lesser number of hours of assistance per patient in intensive care sectors.

The fact that the NAS team calculation is superior to the one of the team estimated by the legislation 
discloses that the accruing workload in the neonatal unit is underestimated by that legislation. Therefore, while resolution COFEN 293/04(10) states 5.6 hours of nursing assistance in the sectors of intermediate care (EBEN and EBEL), the workload obtained by NAS shows an average of 29.1 and 32.6, equivalent to 7 and 8 hours, respectively. The same resolution states for half-intensive care sectors (EBEA) 9.4 hours of assistance per patient, however the average yielded by NAS was 41.9 , equivalent to 10 hours. The EBEI and UBER sectors, considered intensive care units, present an average workload of 85.7 and 86.8, what is equivalent to 20.5 and 21 hours of assistance per patient, respectively; while resolution COFEN 293/04(10) states for such cares 17.9 hours, the ordinance of the Health Ministry ${ }^{(11)} 3432 / 98$ states 19.2 hours and the RDC no. $7 / 10^{(12)} 15$ hours of assistance. The calculation of the staff quantity of the nursing team through standardized hours of given assistance proves to be inadequate, once that each unit of a health institution presents a definitive workload which can have a superior or inferior figure to the one established by the legislation. For the time being, workload measurement tools, as for example NAS, make the accurate measuring of the unit demand, beyond that they make a more credible sizing possible. Therefore, the NAS tool proves adequate for the survey of the neonatal unit workload, what allows for its use as a parameter for the calculation of the nursing team quantity.

\section{Conclusion}

The application of a workload measurement tool (NAS) in the neonatal unit of this study showed that all the sectors presented an excessive workload due to an inadequate staff quantity and a high care demand; the high number of hours of assistance is superior to the hours stated by the legislation; the available team in the service presented a nursing staff quantity substantially inferior when compared with the workload calculation (NAS) or the effective legislation.

Therefore, the evaluation of the unit workload is essential for the adequacy of the number of nursing team professionals and consequent reduction of the workload which the staff members are submitted to, as well as for the quality improvement of the provided assistance.

\section{Acknowledgements}

To Professor Raquel Rapone Gaidzinsk, from the Department of Vocational Guidance at the University of São Paulo School of Nursing, for sharing her knowledge with us and guiding us during this study.

\section{References}

1. Versa GLGS, Inoue KC, Nicola $A L$, Matsuda LM. Influência do dimensionamento da equipe de enfermagem na qualidade do cuidado ao paciente crítico. Texto Contexto Enferm. 2011;20(4):796-802.

2. Conishi RMY, Gaidzinski RR. Nursing Activities Score (NAS) como instrumento para medir carga de trabalho de enfermagem em UTI adulto. Rev Esc Enferm USP. 2007;41(3):346-54.

3. Gonçalves L, Padilha KG. Fatores associados à carga de trabalho de enfermagem em unidade de terapia intensiva. Rev Esc Enferm USP. 2007;41(4):645-52.

4. Fogaça MDC, Carvalho W, Nogueira-Martins LA. Demandas do trabalho e controle: implicações em unidades de terapia intensiva pediátrica e neonatal. Rev Bras Enferm. 2010;63(4):529-32.

5. Miranda DR, Rijk A, Schaufeli W. Simplified Therapeutic Intervention Scoring System: the TISS-28 itens-results from a multicenter study. Crit Care Med. 1996;24(1):64-73.

6. Queijo AF, Padilha KG. Nursing Activities Score (NAS): adaptação transcultural e validação para a língua portuguesa. Rev Esc Enferm USP. 2009;43(10):18-25.

7. Bochembuzio L. Avaliação do instrumento Nursing Activities Score em neonatologia. [tese de doutorado]. São Paulo (SP): Escola de Enfermagem da Universidade de São Paulo; 2007. 157 p.

8. Hausmann M, Peduzzi M. Articulação entre as dimensões gerencial e assistencial do processo de trabalho do enfermeiro. Texto Contexto Enferm. 2009;18(2):258-65.

9. Mello MC. Carga de Trabalho de Enfermagem: Indicadores de Tempo em Unidades de Clínica Médica, Cirúrgica e Terapia Intensiva Adulto. [tese de doutorado]. São Paulo (SP): Escola de Enfermagem da Universidade de São Paulo; 2011. 228 p.

10. Conselho Federal de Enfermagem (BR). Resolução no 293, de 21 de setembro de 2004. Fixa e estabelece parâmetros para dimensionamento do quadro de profissionais de enfermagem nas unidades das instituições de saúde e assemelhados. 2004. [acesso 3 dez 2011]. Disponível em: http://corensp.org. br/072005/

11. Ministério da Saúde (BR). Portaria no 3432, de 12 de agosto de 1998. Estabelece critérios de classificação para as Unidades de Tratamento Intensivo - UTI. 1998. [acesso 3 dez 2011]. Disponível em: http://dtr2001. saude.gov.br/sas/PORTARIAS/PORT98/GM/PRT-3432. pdf 
12. Agência Nacional de Vigilância Sanitária (BR). Resolução no 7, de 24 de fevereiro de 2010. Dispõe sobre os requisitos mínimos para funcionamento de Unidades de Terapia Intensiva e dá outras providências. 2010. [acesso 3 dez 2011]. Disponível em: http:// bvsms.saude.gov.br/bvs/saudelegis/anvisa/2010/ res007_24_02_2010.

13. Kiekkas P, Sakellaropoulos GC, Brokalaki H, Manolis E, Samios A, Skartsani C, et al. Association between nursing workload and mortality of intensive care unit patients. J Nurs Scholar. 2008;40(4):385-90.

14. Hamilton K, Redshaw ME, Tarnow-Mordi W. Nurse staffing in relation to risk-adjusted mortality in neonatal care. Arch Dis Child Fetal Neonatal. 2007;92(2):99-103. 15. Hamilton K, Redshaw M, Tarnow-Mordi W. Nurse staffing in relation to risk-adjusted mortality in neonatal care. Arch Dis Child Fetal Neonatal. 2007;92:99-103. 